\title{
Environmentally Friendly Approach of Controlling Insect Pests in Tomato (Solanum lycopersicum L.)
}

\author{
Amosi Leonard Mbuji ${ }^{1 *}$ Amani Stephen Milinga ${ }^{1,2}$ Vincent Kiswaga \\ 1.College of Resources and Environmental Science, China Agricultural University, No.2 Yuanmingyuan xilu, \\ Haidian District, Beijing 100193, China \\ 2.Tanzania Smallholders Tea Development Agency, Department of Agriculture and Extension Services, \\ P. O Box 5815, First Floor, Tetex House, Pamba Road, Dar es Salaam, Tanzania \\ * Email of corresponding author: amosimbuji@yahoo.com
}

\begin{abstract}
Experiments were conducted at the Sokoine University of Agriculture in Tanzania, located at latitude 06'50'S', longitude 37'39'E and $526 \mathrm{~m}$ above the sea level during the short and long rainy seasons December 2016 and March 2017 and was repeated December 2018 and March 2019. Bio-pesticides were applied at interval of $2^{\text {nd }}, 3^{\text {rd }}$, $4^{\text {th }}$ and $5^{\text {th }}$ week after transplanting. The field was characterized by sandy loam soil with a $\mathrm{pH}$ of 5.16 and annual rainfall ranging from 750 to $1050 \mathrm{~mm}$. During the season the temperature ranged from $26^{\circ} \mathrm{C}$ to $32^{\circ} \mathrm{C}$. The experiment was carried under Randomized Complete Block Design with three replications and three biopesticides as treatments (Castor oil plant, Garlic, Ginger and the Control). The crop was spaced at $90 \mathrm{~cm} \times 60 \mathrm{~cm}$ and each plot sized with area of $13.5 \mathrm{~m}^{2}$ had three rows and six plants per row. The objectives of the study were to determine the most significant pest species affecting the crop and test for the efficacy of selected biopesticides in controlling the observed insect pests on tomato crop. Obtained results suggested that whiteflies (Bemisia tabaci) were the most abundant pest followed by Aphids (Aphis gossypii) while Tuta absoluta and Leaf miners (Liriomyza trifolii) were the least abundant. Garlic, castor oils, and ginger significantly $(\mathrm{P}<0.05)$ suppressed the pest population. This study suggests that $25 \%$ of tomato yield loss was much influenced by insect pests and organic protectants have potential to grossly minimize pest problems to allow the realization of substantial yield and conserve the environment.
\end{abstract}

Keywords: Bio-pesticides; Insect pests; Tomato; Yield.

DOI: $10.7176 / \mathrm{JEES} / 12-2-02$

Publication date: February $28^{\text {th }} 2022$

\section{Introduction}

Tomato (Solanum lycopersicum L.) is ranked second in the world among vegetable crops (Arora et al., 2014;Sumner et al., 2010). It accounts for 14\% of world's vegetable production and the second most important vegetable and popular crop with high per capita consumption ( Huevelink, 2007; Noojibail, 217). Worldwide, China is a leading country in production of tomato followed by Europe (Costa, Miguel, 2007; Huevelink, 2007). Tomato is grown in many parts of Tanzania under small scale farming and it ranks among highly consumed vegetables (Mutayoba and Ngaruko, 2018). Majority of farmers cultivate not more than one hectare per household. Several areas are suitable for the production of the crop in the country but the main producing regions includes; Iringa, Arusha, Mbeya, and Morogoro (H. de Putter, 2015). In Tanzania, cereals and horticulture consume most of the pesticides and it is estimated that every year country imports pesticides from 500 to 2,500 tonnes (Elibariki and Maguta, 2017). There is a major increase of pesticide use in tomato, cabbage, Chinese cabbage, amaranth, maize, and rice production, through intensification, increase of area planted and increased occurrence of pests and diseases. Pesticide's accessibility and affordability is still impeding agriculture sector in Tanzania specifically small-scale farmers because of low purchasing power hence high loss is experienced leading to food insecurity, poor livelihood and finally chronic poverty among rural communities.

Effects of pesticides on vulnerable ecosystems like aquatic ecosystems such as pollution in water, fisheries, pest resistance development and prevent pollination (Lahr et al., 2016). Adverse effects on environment, increase of pest resurgence, and destruction of biodiversity caused by synthetic pesticides and increased of safe food demand by consumers have revitalized investigation on bio-pesticides. In Tanzania, the use of biological materials to protect crops against pests has not well emphasized and there is an extensive base of indigenous knowledge in the application of bio-pesticides materials for managing insect pests have not captured, few biopesticides which have been registered and used by small-scale farmers in Tanzania (Moshi and Matoju, 2017). The present study aimed at contributing to improved tomato yield through effective control of insect pests using bio-pesticides. Specifically, the objective of the study were; i) to quantify the abundance of different insect pests species under different pest control options, and ii) to evaluate losses caused by insect pests on the tomato yield.

\section{Methodology}

Experiments were conducted at Sokoine University of Agriculture -Horticulture unit in Tanzania located at 
latitude $06{ }^{\prime} 50$ 'S', longitude $37^{\prime} 39^{\prime} \mathrm{E}$ and $526 \mathrm{~m}$ above the sea level during the short and long rainy seasons December 2016 and March 2017 and was repeated December 2018 and March 2019. The experiment was set under Randomized Complete Block Design (RCBD) with three replications and four pest control agents as treatments (Castor oil plant, Garlic, Ginger and the Control). The spacing used was $90 \mathrm{~cm} \mathrm{x} 60 \mathrm{~cm}$ and each plot had three rows and six plants per row. DAP and CAN fertilizer was used first week after transplanting and $4^{\text {th }}$ week before fruit setting respectively. $1 \mathrm{~kg}$ of each bio-pesticide which are castor oil plants (Seeds), garlic and ginger were ground and mixed with one and a half-liter of water and was left overnight then was filtered and 1.5 $\mathrm{L}$ of solution of each bio-pesticide was applied once per week. A knapsack sprayer was used to apply biopesticide. The protectants were applied to the crop fortnightly and fresh mixtures were prepared every time when application was required (24 hours before actual use). The experiment was first conducted December 2016 and March 2017 and repeated from December 2018 and March 2019. Bio-pesticides were applied at interval of $2^{\text {nd }}$, $3^{\text {rd }}, 4^{\text {th }}$ and $5^{\text {th }}$ week after transplanting. A digital weighing scale bought from near Agro-chemical shop was used to weigh marketable and unmarketable fruits, weigh (in $\mathrm{kg}$ ) per area was equated to hectare.

\section{Results}

Yellow sticky traps double sided with size $25 \mathrm{~cm}$ x $40 \mathrm{~cm}$ was used to trap Aphids, leaf miners (moths) and whiteflies Black sticky cards double sided with size $25 \mathrm{~cm} \mathrm{x} 40 \mathrm{~cm}$ was used for Tuta absoluta. It has small holes that make it easier to hang the cards. In a young crop, both sticky traps were supported by wire holders and hanged vertically above the ground surface at $30 \mathrm{~cm}$. In mature plants, the traps were hanged $60 \mathrm{~cm}$ above the ground surface, both traps were bought from Sygenta chemical company Limited- Tanzania. The traps were installed in the middle of each plot sized with area of $13.5 \mathrm{~m}^{2}$. Data of insect counts were collected weekly on number of each of pest species three days after administering the organic pesticides. The obtained fruit yield in each treatment including control was counted and weight measured. Collected insect count data were subjected to $\log$ transformation $(\log \mathrm{x}+1)$ to minimize errors prior to statistical analyses in Genstat software (VSN International, 2013). Mean separation test to establish the significance of the tested bio-control agents and derive comparable estimate of yield loss was done by Duncan's Multiple Range Test.

\subsection{Abundance of insect pests under different treatment options}

Table 1 Mean abundance of insect pests infesting tomato crop

\begin{tabular}{lllll}
\hline Treatment & \multicolumn{2}{l}{ Weekly insect pest counts (number/plant) } & \\
\hline & Bemisia tabaci & Tuta absoluta & Aphis gossipii & Liriomyza trifolii \\
Control & 230.6 & 220 & 244 & 275 \\
Castor oil plants & 163.6 & 132.3 & 163.3 & 140 \\
Garlic & 169.6 & 134.7 & 168.7 & 149.3 \\
Ginger & 207.6 & 175.6 & 195.7 & 202.3 \\
F-value & 0.537 & 0.48 & 0.328 & 0.155 \\
CV & 19.21 & 39 & 27.1 & 23.67 \\
S.E.D & 7.85 & 12.22 & 3.16 & 3.62 \\
L.S.D & 38.7 & 31.40 & 11.7 & 23.2 \\
\hline
\end{tabular}




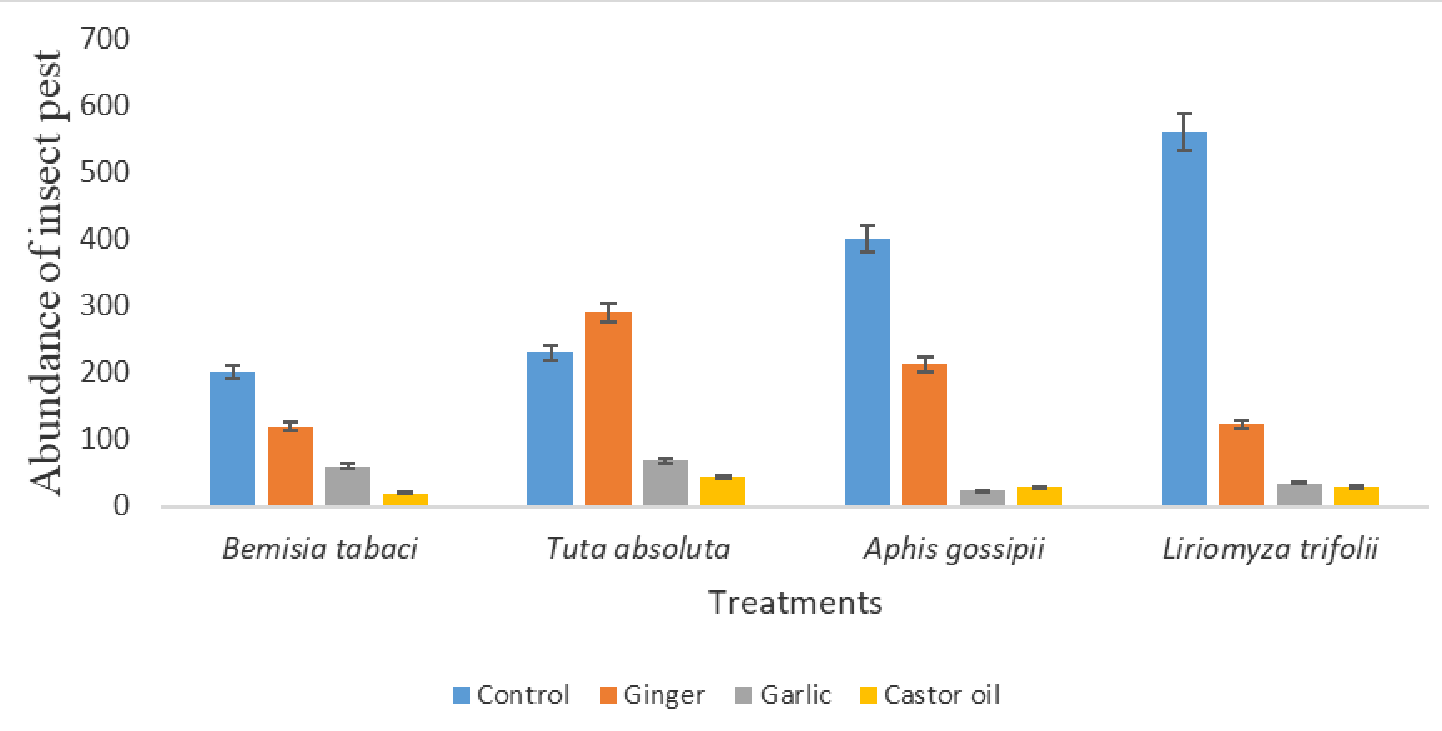

Fig. 1 The graph of insect pests against bio-pesticides

Based on the obtained results (Table 1), the results indicated that castor oil plant has had greatest ability of killing many whiteflies, leaf miners, Tuta absoluta and aphids followed. Statistically, castor oil and garlic performance were not significantly different $(\mathrm{P}>0.05)$ but the difference became significant with ginger and very significant with the control treatment. Thus, the performance-based ranking suggested castor oil to be the effective bio-control agent followed by garlic and ginger while the control (no bio-pesticide) treatment was the least effective (Fig. 1).

\subsection{Tomato yield losses caused by insect pests}

Figure 2 Losses of yield of tomato against bio-pesticides

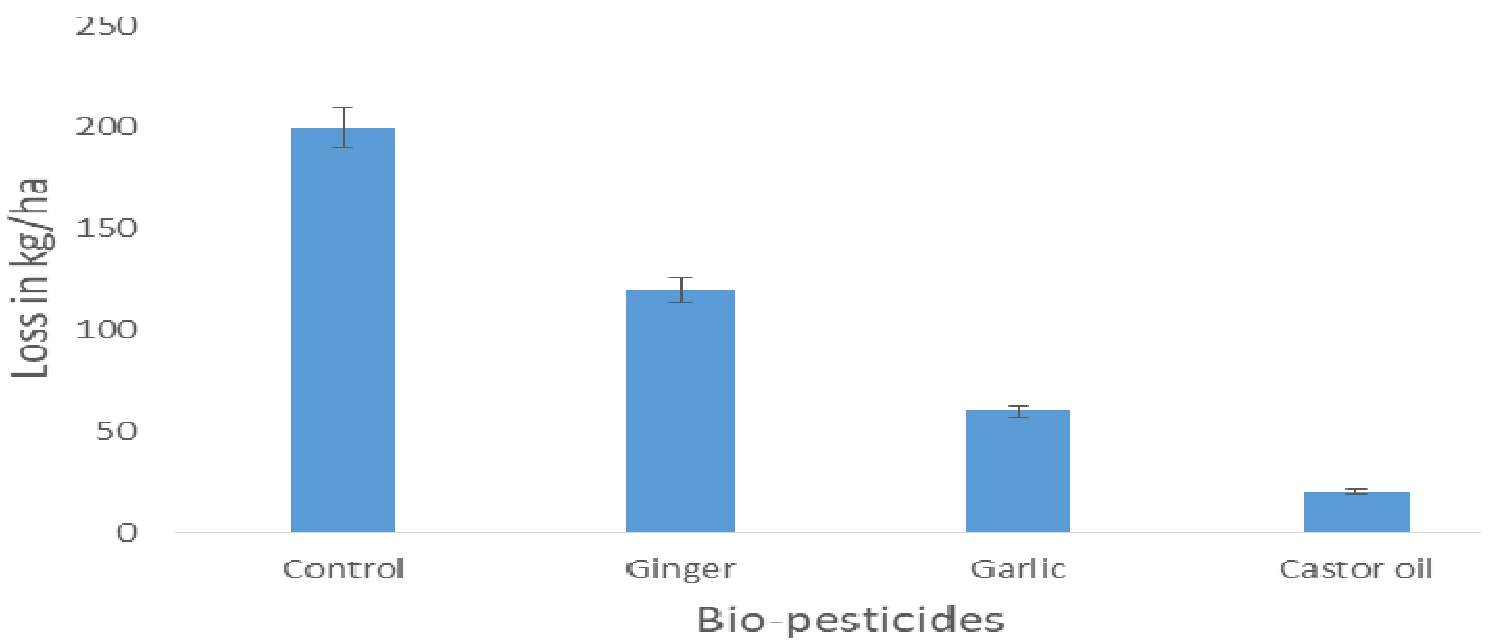

Table 2 Mean for fruit lost

\begin{tabular}{lllll}
\hline During harvest & Week 1 & Week 2 & Week 3 & Week 4 \\
\hline Mean & & & & 275 \\
F-value & 230.6 & 220 & 244 & 0.988 \\
CV & 0.54 & 0.171 & 0.96 & 24.7 \\
S.E.D & 48.2 & 48.3 & 60.4 & 1.179 \\
L.S.D & 1.805 & 1.326 & 1.466 & 2.884 \\
\hline
\end{tabular}

\section{Discussion}

All tested bio-pesticides were generally effective against tomato pests but Castor oil and garlic outperformed ginger. Cowan (1999) reported on the efficacy of castor oil (Ricinus communis) that has ability to control leafeating pests like caterpillars and Japanese beetle due to alkaloids compounds contained in it and has shown the 
efficacy of castor oil to increase with the increase in concentration. The best part of plants proven to work well in insect control was seeds castor oil seeds with 163.6 Bemisia tabaci, 132.3 Tuta absoluta, 163.3 Aphis gossypii, 140 Liriomyza trifolii followed by garlic with insects counts 169.6 Bemisia tabaci, 134.7 Tuta absoluta, 168.7 Aphis gossypii, 149.3 Liriomyza trifolii final ginger accounting 207.6 Bemisia tabaci, 175.6 Tuta absoluta, 195.7 Aphis gossypii, 202.3 Liriomyza trifolii. According to Marceline (2008) also reported on the effectiveness of castor oil plant against aphids, leaf-cutting ants, caterpillars, mites, stink bugs, termites, and also indicated ability of garlic have allicin good for the control of cotton stainers, ladybirds, aphids, flies, armyworms, ticks, ants, beetles, caterpillars, diamondback moths, false codling moths, grubs, mites, peach borers, and termites.

From the results of insect pests and yield losses indicates that castor oil plant had a positive effect in controlling aphids, whiteflies, leaf miners and Tuta absoluta. Castor oil plant has shown a promising future for eggplant gardeners in Nigeria to reduce yield loss from $25 \%-35 \%$ making as a solution to small scale farmers (Ogbu, 2014). Castor oil plant has alkaloids compounds that deter aphids, whiteflies, leaf miners and Tuta absoluta growth and development especially larva (Ayele, 2018), the leaves and seeds of castor plants contain alkaloids compounds responsible in deterring insect pests. Based on data collected the losses in the plots treated with castor plants were little compared with other treatments.

Also, garlic has shown better performance after castor oil plant responding the control of all aphids, whiteflies, leaf miners and Tuta absoluta, the effectiveness of garlic increased as time proceeded soon after transplanting, the first week, second week and third population of aphids, whiteflies, leaf miners and Tuta absoluta due to rainfall wash when sprayed and good performance were caused by strong-smelling of allicin compounds present in it (Debra and Misheck, 2014;Kutawa et al., 2016).

Garlic works well when the environment is dry the application during the wet season is more cumbersome since all applied bio-pesticides get washed by rain. Garlic solution sticks poorly on the surface of plant leaves when is raining it is take off from the surface of the plant and cause a continuous attack by the insect pests. Dry environment cause applied garlic solution to sticky well and other to penetrate in the plant through stomata and lenticels.

The effectiveness of garlic in controlling whiteflies, aphids, leaf miners and Tuta absoluta due to repellant, antifeedants and deterrent nature to insect pests, It contains allicin compounds having repelling nature. Ginger treatment performed poorly to control whiteflies, aphids, leaf miners, and Tuta absoluta leading high produce losses since photosynthesis is hampered. In the selection of bio-pesticides ginger should be in the last choice due to the low capacity of insect pests' control

Generally, castor oil plants should be used as a method of insect pest control in tomato due to having a good response, its affordability, and simplicity of preparation as it requires little knowledge. This could be of advantage to rural farmers who lose most yield to insect pests because of the unaffordability of synthetic insecticides.

Insecticides if are found are high prices causing farmer's crop field infested by insect pests (Donaldson, 2011). To combat the situation there should be a strategic plan enabling the farmer to use materials available to their environment to reduce infestation to a low level of economic damage. Farmer's environment is full of biopesticides alternative to insecticides from which healthy produce is produced (Sharma at el, 2018). The poor farmers in developing countries need access to affordable high-quality insecticides to improve their incomes and reduce malnutrition. Application of bio-pesticides should be encouraged to be used because of conservation of the environment (Gupta and Dikshit, 2010; Talha Nazir, 2016;Baker et al, 2020) when applied in the field never leave toxic residues in soil that hinder and deter microbial activities (Chandler et al., 2011). Xiong et al. (2016) concluded that castor oil plant has a higher efficacy on controlling Liriomyza trifolii at 35\% compared with pepper in tomato and it is a new way for controlling tomato pests due to affordability and accessibility to smallscale farmers and gardeners.

Ginger treatment performed poorly to control whiteflies, aphids, leaf miners and Tuta absoluta leading to high produce losses since photosynthesis is hampered (Lengai and Muthomi, 2018). Poor performance of ginger was caused by rain the bio-pesticide was being washed away this gave a chance for insect pests to attack the crop. In the selection of bio-pesticides ginger should be the choice if the sticker is added up to improve sticking behavior on the plant surface due to the low capacity of insect pests control when it is alone used.

Bio-pesticides promote the safe production of the crops and environment little chemical residuals are retained in the products, soil, air and water (Brust, 2011)

\section{Conclusion}

Hence, we recommend garlic and castor oil plant to be used to control insect pests in tomato crop such as Whiteflies, Leaf miners, Tuta absoluta, and Aphids. From the results indicated that castor oil plant and garlic have great ability to kill many whiteflies, leaf miners, Tuta absoluta, and finally ginger. The low mean of insect pests in garlic and castor oil plant led to low loss of yield, few fruits found damaged by insect pests. So there a significant difference between treatments. 


\section{Conflict of interest}

There is no existing conflict of interest neither between the authors nor institutions

\section{Acknowledgments}

We would like to thanks Ministry of education, Vocational, and Training for financial support during this project moreover we extend our thanks to Professor Maulid W. Mwatawala for guiding us in the whole study.

\section{References}

Arora, S. et al. (2014) 'Biopesticide formulation to control tomato lepidopteran pest menace', Asian AgriHistory, 18(3), pp. 283-293.

Ayele, B. A. (2018) 'Tomato leafminer [( Tuta absoluta Meyrick ) ( Lepidoptera : Gelechiidae )] and its current ecofriendly management strategies : A review', (July), pp. 10-24. doi: 10.5897/JABSD2018.0306.

Baker, B. P., Green, T. A. and Loker, A. J. (2020) 'Biological control and integrated pest management in organic and conventional systems', Biological Control. Elsevier, 140(August 2019), p. 104095. doi: 10.1016/j.biocontrol.2019.104095.

Brust, G. E. (2011) 'Using biopesticides and reduced-risk pesticides for insect control in high tunnel vegetable production', pp. 1-13.

Chandler, D. et al. (2011) 'The development, regulation and use of biopesticides for integrated pest management', pp. 1987-1998. doi: 10.1098/rstb.2010.0390.

Costa, Miguel; Huevelink, E. (2007) 'Today 's worldwide tomato production', International Suppliers Guide, (January), pp. 2006-2008.

Cowan, M. M. (1999) 'Plant products as antimicrobial agents.', 12(4), pp. 564-582.

Debra, K. R. and Misheck, D. (2014) 'Onion (Allium cepa) and garlic (Allium sativum) as pest control intercrops in cabbage based intercrop systems in Zimbabwe', IOSR Journal of Agriculture and Veterinary Science, 7(2), pp. 13-17. doi: 10.9790/2380-07221317.

Donaldson, Dean R, (2011). Todays_world_tomato_14-16_FVT6_6 (1).pdf', University of California Division of Agriculture and Natural Resources, pp. 1-2.

Gupta, S. and Dikshit, A. K. (2010) 'Biopesticides: An ecofriendly approach for pest control', Journal of Biopesticides, 3(1 SPEC.ISSUE), pp. 186-188.

H. de Putter, M. J. van K. and C. L. M. de V. (2015) 'AfriVeg', (August).

Kutawa, A. B. et al. (2016) 'Biopesticides for Pests Control: a Review Biopesticides for Pests Control: a Review', Journal of Biopesticides and Agriculture, 3(1).

Lahr, J. et al. (2016) 'Pesticides in the Southern Agricultural Growth Corridor of Tanzania ( SAGCOT )'.

Lengai, G. M. W. and Muthomi, J. W. (2018) 'Biopesticides and Their Role in Sustainable Agricultural Production', Journal of Biosciences and Medicines, 06(06), pp. 7-41. doi: 10.4236/jbm.2018.66002.

Moshi, A. P. and Matoju, I. (2017) 'The status of research on and application of biopesticides in Tanzania . Review', Crop Protection. Elsevier Ltd, 92, pp. 16-28. doi: 10.1016/j.cropro.2016.10.008.

Mutayoba, V. and Ngaruko, D. (2018) 'Assessing Tomato Farming and Marketing Among Smallholders in High Potential Agricultural Areas of Tanzania', International Journal of Economics, Commerce and Management (IJECM), VI(8), pp. 577-590.

Ogbu, J. U. (2014) 'Efficacy Of Plant Derived Insecticides For Control Of Insect Pests Of Garden Egg ( Solanum Spp .) In Southeastern Nigeria', (August).

Praveen Noojibail. (2017) 'Tomato: Challenges and opportunities in South Asia

Raheli Elibariki, Mihayo Musabila Maguta, (2017), Status of pesticides pollution in Tanzania - A Review, Chemosphere doi: 10.1016/j.chemosphere.2017.03.036

Sharma, K. R., Raju, S. and Thakur, S. (2018) 'BIOPESTICIDES : AN EFFECTIVE TOOL FOR INSECT PEST MANAGEMENT AND Indian Journal of Agriculture', (July).

Sumner, P. E. et al. (2010) 'Commercial Tomato Production Handbook', (October 2015).

Talha Nazir, S. K. and D. Q. (2016) 'Biological Control of Insect Pest', Intech, i(tourism), p. 13. doi: http://dx.doi.org/10.5772/57353.

Xiong, X. et al. (2016) 'The botanical pesticide derived from Sophora flavescens for controlling insect pests can also improve growth and development of tomato plants', Industrial Crops and Products. Elsevier B.V., 92(December 2016), pp. 13-18. doi: 10.1016/j.indcrop.2016.07.043. 


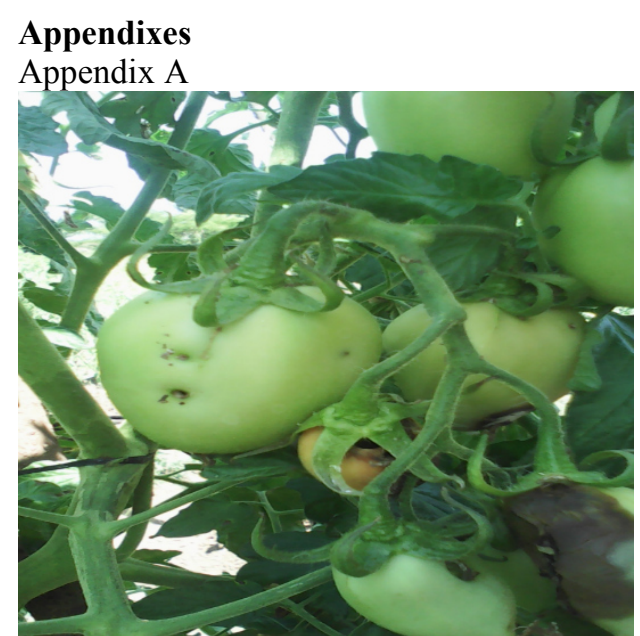

Fruit affected by Tuta absoluta

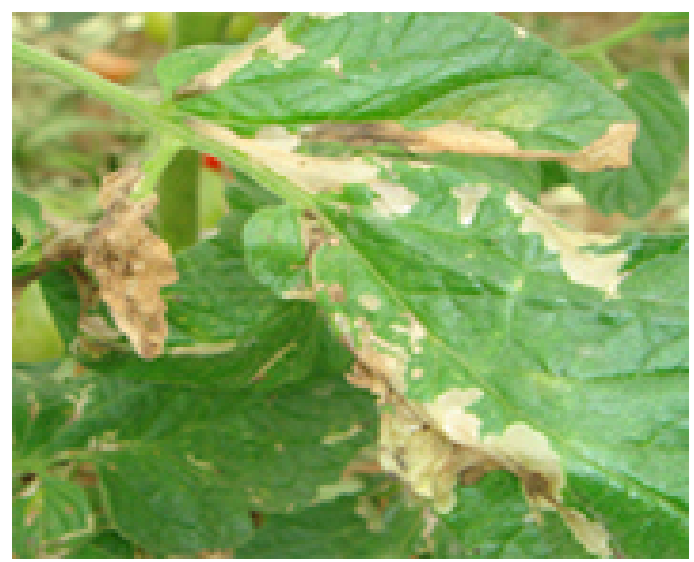

Leaf affected by Tuta absoluta

\section{Appendix B}

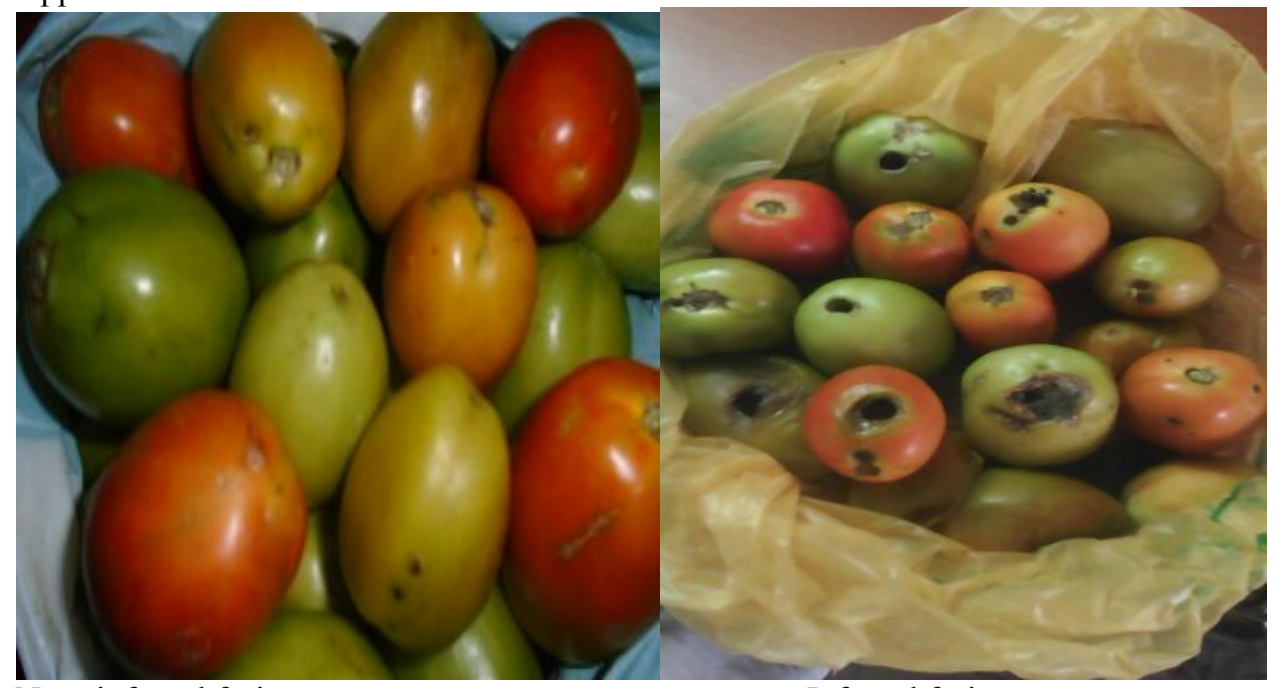

Non- infested fruits

Infested fruits 